\title{
Clinical characteristics and risk factors of nonalcoholic fatty liver disease in children with obesity
}

\author{
Luting Peng', Su Wu², Nan Zhou', Shanliang Zhu ${ }^{3}$, Qianqi Liu ${ }^{1}$ and Xiaonan Li $i^{1,4^{*}}$
}

\begin{abstract}
Background: With the increasing number of children with obesity worldwide, nonalcoholic fatty liver disease (NAFLD) has become the most common liver disease among children. It is necessary to recognize the risk factors of NAFLD for prevention in childhood since NAFLD is asymptomatic in the early stage. Objectives. The objective of this study was to investigate possible risk factors of NAFLD in children with obesity, providing evidence for monitoring and prevention strategies at an early stage for obese children with NAFLD.

Methods: Data were collected from 428 children and adolescents aged 6-16 years recruited from the Children's Hospital at Nanjing Medical University from September 2015 to April 2018 and analyzed. Based on a combination of ultrasound results and alanine transaminase levels, subjects were divided into three groups: simple obesity (SOB), simple steatosis (SS), and nonalcoholic fatty hepatitis (NASH). Blood biochemical examination included glucose, insulin, uric acid, lipid profile and liver enzymes.

Results: Among 428 children with obesity, 235 (54.9\%) had SS and 45 (10.5\%) had NASH. Body mass index, body mass index standard deviation score (BMI-SDS), waist circumference, body fat, liver enzymes, uric acid and HOMA-IR level were significantly higher in the NASH group than in the SS and SOB groups $(p<0.001) .53 .3 \%$ of the SS group and $49.8 \%$ of the NASH group had metabolic syndrome, significantly more than in the SOB group $(19.6 \%, p<$ 0.001). After adjustment for confounding factors, logistic regression models revealed that NASH was associated with BMI-SDS $\geq 3$, gender, hyperuricemia and insulin resistance.

Conclusions: The prevalence of NASH in children with obesity is closely related to high BMI-SDS, gender, insulin resistance and hyperuricemia. These findings provide evidence that monitoring risk factors of childhood obesity can assist in developing prevention strategies for liver disease at an early stage.
\end{abstract}

Keywords: Obese children, Nonalcoholic fatty liver disease, Nonalcoholic steatohepatitis, Gender, Uric acid, Insulin resistance

\footnotetext{
*Correspondence: xiaonan6189@163.com

'Department of Children Health Care, Children's Hospital of Nanjing Medical University, 72 Guangzhou Road, Nanjing 210008, People's Republic of China ${ }^{4}$ Institute of Pediatric Research, Nanjing Medical University, Nanjing 210008, China

Full list of author information is available at the end of the article
}

(c) The Author(s). 2021 Open Access This article is licensed under a Creative Commons Attribution 4.0 International License, which permits use, sharing, adaptation, distribution and reproduction in any medium or format, as long as you give appropriate credit to the original author(s) and the source, provide a link to the Creative Commons licence, and indicate if changes were made. The images or other third party material in this article are included in the article's Creative Commons licence, unless indicated otherwise in a credit line to the material. If material is not included in the article's Creative Commons licence and your intended use is not permitted by statutory regulation or exceeds the permitted use, you will need to obtain permission directly from the copyright holder. To view a copy of this licence, visit http://creativecommons.org/licenses/by/4.0/. The Creative Commons Public Domain Dedication waiver (http://creativecommons.org/publicdomain/zero/1.0/) applies to the data made available in this article, unless otherwise stated in a credit line to the data. 


\section{Background}

With childhood obesity rates increasing, nonalcoholic fatty liver disease (NAFLD) has become the most common liver disease among children worldwide [1]. The prevalence of NAFLD in Chinese children was 3.4\% [2]. The prevalence in obese and overweight children was significantly higher, ranging from 50 to $80 \%$ [3]. NAFLD may progress from simple steatosis (SS) to nonalcoholic steatohepatitis (NASH), subsequently leading to fibrosis/ cirrhosis $[4,5]$. Among those obese youth with NAFLD, $10 \%$ have NASH, characterized by hepatocyte inflammation and expansion in the background of hepatic steatosis [1, 6-8]. Although simple hepatic steatosis usually has a "benign procedure", NASH may degenerate into end-stage liver disease. Children can develop to a harmful stage faster than adults [9]. Liver cirrhosis due to NAFLD in children has been described [10].

In addition to intrahepatic lesions, NAFLD also has serious health consequences beyond the liver associated with metabolic disorder, cardiovascular disease and insulin resistance $[11,12]$. Among patients with nonalcoholic steatohepatitis, half of the deaths were due to cardiovascular disease and malignancy [13, 14]. Therefore, early identification of SS and NASH is crucial for treatment and prognosis.

Liver biopsy is considered the gold standard for the diagnosis of NAFLD, which can facilitate the differentiation of SS and NASH in both children and adults [15]. However, it is not suitable for screening among children because of its invasive nature and cost. In addition, only a small portion of the liver is examined, which may lead to sample errors and selection bias. A noninvasive and qualitative alternative is to examine steatosis of the liver by ultrasound [15]. In addition, blood alanine transaminase (ALT) is an inexpensive, minimally invasive, acceptable and universally available blood test. NAFLD is the most common cause of elevated liver enzymes in patients in developed countries. NASH is associated with a two-fold increase in ALT in children with obesity [15, $16]$.

Studies in adults have shown the link between NAFLD and metabolic disorders [17]. Longitudinal studies in adults demonstrate that patients with NAFLD have increased incidence of diabetes, metabolic syndrome and mortality compared with matched control populations [18]. However, studies on the associations between epidemiological situations, risk factors and cardiovascular risk of NAFLD in obese children are few, especially in China. Children are in a rapid growth and development period, and their pathophysiological changes are different from those of adults. Today's children with obesity are also exposed to maternal obesity and insulin resistance earlier than those decades ago. Like other liver diseases, NAFLD is asymptomatic in the early stage, and can easily go unnoticed by clinicians. This clinical study aimed to investigate possible risk factors of NAFLD in obese children in the Chinese population, specifically the city of Nanjing.

\section{Methods}

\section{Subjects and inclusion criteria}

This study was performed in Nanjing, China, at the Children's Hospital of Nanjing Medical University. The study protocol was approved by the Medical Ethics Committee of the Children's Hospital of Nanjing Medical University (201412004.1). Children from 6 to 16 years old were recruited to the study from September 2015 to April 2018. The study was conducted in obese children. Inclusion criterion was body mass index (BMI) $\geq 95$ th percentile according to China's children's BMI classification. Exclusion criteria were any other endocrine diseases, viral hepatitis, hereditary diseases and other infectious or chronic diseases.

Pubertal stage was evaluated on the basis of the Tanner scale. Children with obesity were further divided into three subgroups by combining ultrasound and ALT 2fold elevation: simple obese (SOB) group with normal liver in ultrasound, simple steatosis (SS) group with fatty liver in ultrasound and ALT $<80 \mathrm{U} / \mathrm{L}$, and NASH group with fatty liver in ultrasound and ALT $\geq 80 \mathrm{U} / \mathrm{L}$, according to the two-fold lab reference standard for impaired liver function [15].

Study staff gave oral and written information to parents/caregivers. The parent(s) or caregiver(s) of all subjects provided written informed consent before inclusion in the study. Written assent was obtained for all children. Through interview with children and their parents, experienced interviewers collected the basic information about the children, including birth history, family history and lifestyles.

\section{Anthropometric measurements}

All participants had anthropometric assessments. Experienced researchers measured height and weight using standardized measuring methods [19]. A digital scale (graduation $100 \mathrm{~g}$ ) was used for weight measurement, and a gauge (graduation $1 \mathrm{~mm}$ ) (Seca 704, Germany) for height measurement. BMI was calculated by dividing body weight (in kilograms) by the square of height (in meters). BMI standard deviation score (BMI-SDS) was calculated according to WHO reference values. At the end of the expiratory period, the waist circumference was measured at the navel with a non-retractable soft ruler to the nearest $0.1 \mathrm{~cm}$ [20]. Waist circumference (in centimeters) was divided by height (in centimeters) to calculate the waist to height ratio (WHtR). Body fat and skeletal muscle were measured by InBody J20 (Biospace, Korea). Percentage of body fat and percentage of skeletal 
muscle were calculated. After a quiet rest for $10 \mathrm{~min}$, blood pressure was measured three times by an electronic sphygmomanometer (Omron HBP-1300) and the mean value was taken.

\section{Blood biochemical examination}

All subjects were told to fast overnight for $12 \mathrm{~h}$ before phlebotomy the next morning. Fasting laboratory assays included glucose, insulin, total cholesterol, high-density lipoprotein (HDL) cholesterol, triglycerides, alanine aminotransferase (ALT), and aspartate aminotransferase (AST).

\section{Abdominal ultrasound examination}

All subjects were examined after $12 \mathrm{~h}$ of fasting overnight. Hepatic ultrasonography was performed by ultrasound technician to establish a diagnosis according to at least two of the following criteria: higher echogenicity higher in the liver than in the spleen or kidney; blurred hepatic vasculature; high attenuation of signals [21].

\section{Definitions for metabolic syndrome and cardiovascular risk factors}

The diagnosis of metabolic syndrome was defined as having at least three criteria with the following cut points [22]: abdominal obesity (waist circumference $\geq$ 90th percentile of waist circumference of children of the same age and gender [23], elevated triglycerides $(\geq 1.47$ $\mathrm{mmol} / \mathrm{L}[130 \mathrm{mg} / \mathrm{dL}])$ [24], low HDL cholesterol $(<1.03$ $\mathrm{mmol} / \mathrm{L}[40 \mathrm{mg} / \mathrm{dL}]$ ), elevated blood pressure [systolic blood pressure (SBP) $\geq 90$ th percentile of SBP or diastolic blood pressure (DBP) $\geq 90$ th percentile of DBP of children of the same age and height and gender], and impaired fasting glucose $(\geq 5.6 \mathrm{mmol} / \mathrm{L}[100 \mathrm{mg} / \mathrm{dL}])$. In addition to the factors of metabolic syndrome, insulin resistance was defined according to homeostasis model assessment of insulin resistance (HOMA-IR) which was calculated as fasting insulin $(\mathrm{mU} / \mathrm{mL}) \times$ [fasting glucose $(\mathrm{mmol} / \mathrm{L}) / 22.5]$ [25]. The insulin resistance threshold was defined as $\geq 3.16$, as described in the literature [26]. Hyperuricemia was defined as uric acid value $\geq 357 \mathrm{umol}$ /L [27].

\section{Statistical analysis}

All statistical analysis was performed with SPSS version 25.0 software (SPSS Inc., Chicago, Illinois). Quantitative data with normal distribution were expressed as mean \pm SD. One-way ANOVA was used to test differences among of the three groups, and multiple testing was analyzed with the least significant difference method. Quantitative data with non-normal distribution were expressed as median with interquartile range. The Kruskal-Wallis test was used to test differences among the three groups, and the Mann-Whitney $\mathrm{U}$ test was used for comparison between groups. Chi-square tests were performed for the differences in proportions, and odds ratio (OR) value and 95\% confidence interval (CI) were calculated. Logistic dichotomous regression analysis was used to test NASH risk factors, and the adjusted OR and 95\% CI were given. The significance level was defined at $p<0.05$.

\section{Results}

Demographic and clinical characteristics of participants A total of 428 children with obesity were recruited for the study, including 148 (34.6\%) with SOB, 235 (54.9\%) with SS and 45 (10.5\%) with NASH. Anthropometric characteristics are shown in Table 1. There was no significant difference in age or Tanner stage classification among the three groups. Obesity indicators such as BMI, BMI-SDS, waist circumference, and Body fat in the NASH group were significantly higher than in the SS and $\mathrm{SOB}$ groups, but percentage of skeletal muscle in the NASH group was significantly lower than in the other groups $(p<0.001)$. Percentage of body fat and WHtR in the SS and NASH groups were significantly higher than in the SOB group, but there was no significant difference between the first two groups, indicating that these two anthropometric measurements could not well distinguish the spectrum of NAFLD.

\section{Comparison of biochemical parameters in children with obesity with or without NAFLD}

The biochemical parameters are shown in Table 2. Children in the NASH group had higher hepatic enzymes including ALT and AST, indicating liver injury. The triglyceride levels were significantly higher in the NASH and SS groups compared with the SOB group. The uric acid concentration and HOMA-IR levels involved in the pathogenesis of NAFLD were ranked as follows: $\mathrm{SOB}<$ $\mathrm{SS}<\mathrm{NASH}$.

\section{Prevalence of metabolic syndrome and cardiovascular risk} factors in NAFLD compared with children without NAFLD

The occurrence rates of metabolic syndrome in the NASH and SS groups were significantly higher than in the SOB group (53.3, $49.8 \%$ vs $19.6 \%, p<0.001)$. Children with NASH had significantly elevated blood pressure and triglycerides compared with children in the SOB group, but there was no difference in the frequency of abdominal obesity, low HDL and impaired fasting glucose when dichotomous cut points were used among groups (Table 3).

Further investigation indicated that the prevalence of insulin resistance $(38.5 \%$ / 46.8\% / 68.9\%) and hyperuricemia $(45.9 \%$ / 68.5\% /86.7\%) were steadily higher from the SOB group to the SS group to the NASH group, respectively $(p<0.001)$. The progression of NAFLD was 
Table 1 Comparison of anthropometric measurements

\begin{tabular}{|c|c|c|c|c|c|}
\hline \multirow[t]{2}{*}{ Groups } & \multirow[t]{2}{*}{ SOB } & \multicolumn{2}{|l|}{ NAFLD } & \multirow{2}{*}{$\begin{array}{l}F / Z / \\
x^{2}\end{array}$} & \multirow{2}{*}{$\begin{array}{l}p- \\
\text { value }\end{array}$} \\
\hline & & SS & NASH & & \\
\hline$N(\mathrm{M} / \mathrm{F})$ & $148(96 / 52)$ & $235(161 / 74)$ & $45(42 / 3)$ & 13.73 & 0.001 \\
\hline Age (y) & $10.19 \pm 1.76$ & $10.46 \pm 1.71$ & $10.65 \pm 1.76$ & 1.71 & 0.181 \\
\hline Tanner Stage, $n(\%)$ & & & & 4.38 & 0.357 \\
\hline 1 & $86(58.90 \%)$ & $127(55.70 \%)$ & $23(51.10 \%)$ & & \\
\hline $2-3$ & $53(36.30 \%)$ & $88(38.60 \%)$ & $22(48.90 \%)$ & & \\
\hline $4-5$ & $7(4.80 \%)$ & $13(5.70 \%)$ & $0(0.00 \%)$ & & \\
\hline BMI $\left(\mathrm{kg} / \mathrm{m}^{2}\right)$ & $25.16(2.79)^{\mathrm{ab}}$ & $28.14(3.93)^{\mathrm{a}}$ & $29.45(4.42)$ & 39.75 & 0.001 \\
\hline BMI-SDS & $2.72(0.76)^{\mathrm{ab}}$ & $3.20(0.89)^{a}$ & $3.60(0.98)$ & 21.83 & 0.001 \\
\hline Body fat (kg) & $20.50(5.87)^{\mathrm{ab}}$ & $26.67(8.38)^{a}$ & $29.33(10.29)$ & 35.91 & 0.001 \\
\hline Percentage of body fat (\%) & $37.12 \pm 5.38^{\mathrm{ab}}$ & $40.40 \pm 6.10$ & $41.06 \pm 6.27$ & 16.15 & 0.001 \\
\hline Skeletal muscle (kg) & $18.24 \pm 4.53^{\mathrm{ab}}$ & $20.58 \pm 5.35$ & $22.25 \pm 6.99$ & 13.03 & 0.001 \\
\hline Percentage of skeletal muscle (\%) & $33.01 \pm 3.14^{\mathrm{ab}}$ & $31.69 \pm 3.43^{\mathrm{a}}$ & $30.17 \pm 4.78$ & 11.64 & 0.001 \\
\hline Waist circumference $(\mathrm{cm})$ & $83.62 \pm 8.48^{\mathrm{ab}}$ & $92.50 \pm 10.45^{a}$ & $96.14 \pm 10.25$ & 45.26 & 0.001 \\
\hline WHtR (\%) & $0.57 \pm 0.05^{\mathrm{ab}}$ & $0.61 \pm 0.05$ & $0.63 \pm 0.04$ & 35.42 & 0.001 \\
\hline $\mathrm{SBP}(\mathrm{mmHg})$ & $111 \pm 15^{\mathrm{ab}}$ & $116 \pm 16^{a}$ & $123 \pm 16$ & 11.86 & 0.001 \\
\hline $\mathrm{DBP}(\mathrm{mmHg})$ & $65 \pm 10^{\mathrm{ab}}$ & $69 \pm 10$ & $71 \pm 10$ & 8.01 & 0.001 \\
\hline
\end{tabular}

Normal distribution data are expressed as the mean \pm SD. Non-normal distribution data are presented as median (interquartile). vs. NASH group, ${ }^{a} p<0.001 ;$ vs. SS group, ${ }^{\mathrm{b}} p<0.001$

SOB Simple Obese, NAFLD Nonalcoholic Fatty Liver Disease, SS Simple Steatosis, NASH Nonalcoholic Fatty Hepatitis, M Male, F Female, BMI Body Mass Index, BMISDS Body Mass Index Standard deviation score, WHtR Waist to height ratio, SBP Systolic blood pressure, DBP Diastolic blood pressure

positively associated with cardiovascular risk factors and metabolic syndrome in these children with obesity. As shown in Fig. 1, all children in the SS and NASH groups had at least one metabolic syndrome factor. Moreover, the distribution of metabolic syndrome features in children in the NASH and SS groups was significantly $(p<$ 0.001 ) shifted to the right, with more features present than in children with obesity in the SOB group.

\section{Correlates of NASH with obesity or metabolic risks}

After adjusting for all other variables among the children with obesity, the odds of having NASH were significantly higher in those with severe obesity (BMI-SDS $\geq 3$ ) (OR 2.56; 95\% CI 1.06-6.17) compared to those with mild obesity, males (OR 4.94; 95\% CI 1.41-17.35) compared to females, those with hyperuricemia (OR 2.98; $95 \% \mathrm{CI}$ 1.14-7.76) compared to those without hyperuricemia, and those with insulin resistance (OR 2.71; 95\% CI 1.29-

Table 2 Comparison of biochemical parameters between SOB and NAFLD

\begin{tabular}{|c|c|c|c|c|c|}
\hline \multirow[t]{2}{*}{ Groups } & \multirow[t]{2}{*}{ SOB } & \multicolumn{2}{|l|}{ NAFLD } & \multirow[t]{2}{*}{$F / Z$} & \multirow[t]{2}{*}{$p$-value } \\
\hline & & SS & NASH & & \\
\hline $\mathrm{ALT}(\mathrm{U} / \mathrm{L})$ & $17(9)^{\mathrm{ab}}$ & $26(21)^{\mathrm{a}}$ & $106(41)$ & 161.92 & 0.001 \\
\hline AST (U/L) & $22(8)^{\mathrm{ab}}$ & $26(14)^{\mathrm{a}}$ & $62(26)$ & 112.41 & 0.001 \\
\hline Uric acid ( $\mu \mathrm{mol} / \mathrm{L})$ & $352(96)^{a b}$ & $406(124)^{a}$ & $455(141)$ & 49.96 & 0.001 \\
\hline Triglycerides (mmol/L) & $1.05(0.62)^{\mathrm{ab}}$ & $1.37(0.91)$ & $1.31(0.90)$ & 16.83 & 0.001 \\
\hline Cholesterol (mmol/L) & $4.25 \pm 0.99^{\mathrm{a}}$ & $4.33 \pm 0.89$ & $4.59 \pm 0.88$ & 2.29 & 0.103 \\
\hline HDL (mmol/L) & $1.27(0.37)^{b}$ & $1.17(0.36)$ & $1.18(0.30)$ & 18.23 & 0.001 \\
\hline Fasting glucose (mmol/L) & $4.73 \pm 0.44^{b}$ & $4.61 \pm 0.48$ & $4.61 \pm 0.59$ & 3.08 & 0.047 \\
\hline Fasting insulin (mU/L) & $12.71(12.08)^{a}$ & $15.01(14.39)^{\mathrm{a}}$ & $21.30(7.60)$ & 12.39 & 0.002 \\
\hline HOMA-IR & $2.77(2.53)^{a}$ & $3.06(3.00)^{a}$ & $4.2(4.61)$ & 10.39 & 0.006 \\
\hline
\end{tabular}

vs. NASH group, ${ }^{a} p<0.001$; vs. SS group, ${ }^{b} p<0.001$. Normal distribution data are expressed as the mean \pm SD. Non-normal distribution data are presented as median (interquartile)

SOB Simple Obese, NAFLD Nonalcoholic Fatty Liver Disease, SS Simple Steatosis, NASH Nonalcoholic Fatty Hepatitis, ALT Alanine aminotransferase, AST Aspartate aminotransferase, HDL High-density lipoprotein, HOMA-IR Homeostasis model assessment of insulin resistance 
Table 3 Comparisons of metabolic risk factors between obese children with NAFLD and those without liver disorder

\begin{tabular}{|c|c|c|c|c|c|}
\hline \multirow[t]{2}{*}{ Factors } & \multirow{2}{*}{$\begin{array}{l}\text { SOB }(N= \\
148)\end{array}$} & \multicolumn{2}{|l|}{ NAFLD } & \multirow[t]{2}{*}{$x^{2}$} & \multirow[t]{2}{*}{$p$-value } \\
\hline & & SS $(N=235)$ & NASH $(N=45)$ & & \\
\hline \multicolumn{6}{|l|}{ Abdominal obesity } \\
\hline Waist circumference $(\mathrm{cm}) \geq \mathrm{p} 90, \%$ & $144(97.3 \%)$ & $234(99.6 \%)$ & $45(100.0 \%)$ & 4.67 & 0.097 \\
\hline \multicolumn{6}{|l|}{ Elevated blood pressure } \\
\hline $\mathrm{SBP}$ or $\mathrm{DBP} \geq \mathrm{p} 90, \%$ & $62(41.9 \%)^{a}$ & $146(62.1 \%)$ & $30(66.7 \%)$ & 17.56 & 0.001 \\
\hline \multicolumn{6}{|l|}{ Dyslipidemia } \\
\hline Triglycerides $(\mathrm{mmol} / \mathrm{L}) \geq 1.47 \mathrm{mmol} / \mathrm{L}, \%$ & $57(38.5 \%)^{a b}$ & 133 (56.6\%) & $27(60 . \%)$ & 13.44 & 0.001 \\
\hline $\mathrm{HDL}(\mathrm{mmol} / \mathrm{L})<1.03 \mathrm{mmol} / \mathrm{L}, \%$ & $15(10.1 \%)^{b}$ & 65 (27.7\%) & $8(17.8 \%)$ & 17.63 & 0.001 \\
\hline \multicolumn{6}{|l|}{ Impaired fasting glucose } \\
\hline Fasting Glucose $\geq 5.6 \mathrm{mmol} / \mathrm{L}, \%$ & $2(1.4 \%)$ & $6(2.6 \%)$ & $2(4.4 \%)$ & 1.55 & 0.460 \\
\hline \multicolumn{6}{|l|}{ Insulin resistance } \\
\hline HOMA-IR ( $\geq 3.16), \%$ & $57(38.5 \%)^{a b}$ & $110(46.8 \%)^{\mathrm{a}}$ & $31(68.9 \%)$ & 12.87 & 0.002 \\
\hline \multicolumn{6}{|l|}{ Hyperuricemia } \\
\hline Uric Acid (umol/L) $\geq 357$ umol/L, $\%$ & $68(45.9 \%)^{\mathrm{ab}}$ & $161(68.5 \%)^{\mathrm{a}}$ & $39(86.7 \%)$ & 32.63 & 0.001 \\
\hline Metabolic syndrome, \% & $29(19.6 \%)^{a b}$ & $117(49.8 \%)$ & 24 (53.3\%) & 38.47 & 0.001 \\
\hline
\end{tabular}

5.69) compared to those without insulin resistance (see Table 4).

\section{Discussion}

Clinical characteristics of NAFLD in children with obesity In the context of the obesity epidemic among children in China, the rate of NAFLD has become increasingly serious in the past 20 years. In this study of 428 children with obesity, $54.9 \%$ had NAFLD, and $10.5 \%$ NASH. Moreover, children with NAFLD had a higher risk of cardiovascular and metabolic syndrome than those without it. Severe obesity, gender, hyperuricemia and insulin resistance are risk factors for $\mathrm{NASH}$ in children with obesity. Clinical evidence indicates that children with
NAFLD experience an increased incidence and mortality of cardiovascular disease in adulthood [9]. Early identification of the clinical characteristics is therefore particularly important for Chinese children with NAFLD and NASH in light of the current obesity epidemic.

Due to differences in diagnostic criteria, selected population and ethnicity, the reported prevalence of NAFLD varies greatly in the literature [3]. A metaanalysis of epidemiological studies in children showed that an average prevalence of NAFLD was $7.6 \%$ in general population studies and $34.2 \%$ in studies of children with obesity [3]. Due to the limitations of the invasive diagnostic methods for $\mathrm{NASH}$, there is currently a lack of population-based studies on NASH. A recent

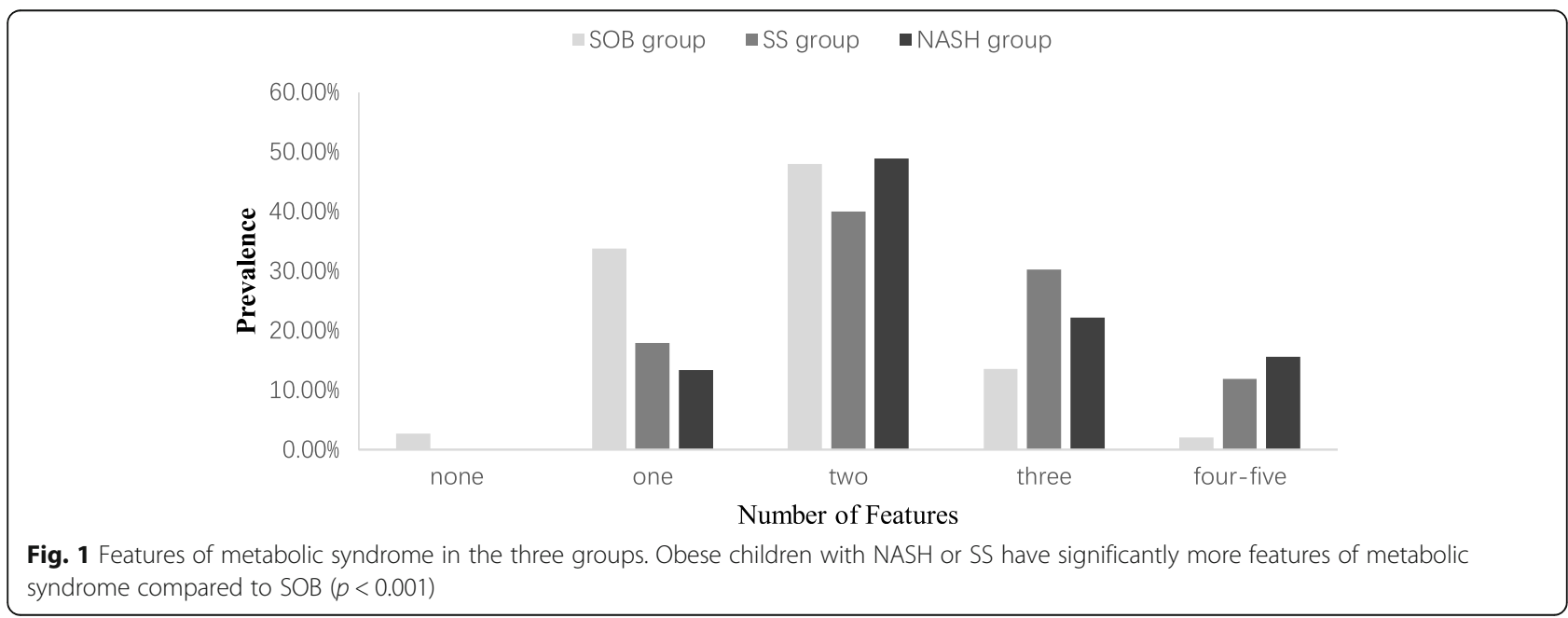


Table 4 Logistic regression analysis of the correlates associated with NASH

\begin{tabular}{|c|c|c|}
\hline & Adjusted OR (95\% Cl) & $p$-value \\
\hline \multicolumn{3}{|l|}{ BMI-SDS category } \\
\hline $2 \leq \mathrm{BMI}-\mathrm{SDS}<3^{\mathrm{r}}$ & 1 & \\
\hline BMI-SDS $\geq 3$ & $2.56(1.06-6.17)$ & 0.037 \\
\hline \multicolumn{3}{|l|}{ Gender } \\
\hline Females $^{r}$ & 1 & \\
\hline Males & $4.94(1.41-17.35)$ & 0.013 \\
\hline \multicolumn{3}{|l|}{ Hyperuricemia } \\
\hline $\mathrm{No}^{r}$ & 1 & \\
\hline Yes & $2.98(1.14-7.76)$ & 0.025 \\
\hline \multicolumn{3}{|l|}{ Insulin resistance } \\
\hline $\mathrm{No}^{r}$ & 1 & \\
\hline Yes & $2.71(1.29-5.69)$ & 0.009 \\
\hline
\end{tabular}

Note: ${ }^{r}$ Reference category. Variables included in the adjusted model were age, gender, Tanner stage, BMI-SDS category, abdominal obesity, elevated blood pressure, hyperuricemia, impaired fasting glucose, insulin resistance, low HDL and elevated triglycerides

CI Confidence interval, OR Odds ratio, BMI-SDS Standard deviation score for the body mass index

community-based study reported that 193 subjects (55\%) were diagnosed with NAFLD, and 105 subjects (30\%) were diagnosed with NASH by biopsy [16]. In our study, the incidence of NAFLD in children with obesity was $65.4 \%$, which was higher than other reports, and the incidence of NASH was $10.5 \%$. The risk of NASH in severely obese (BMI-SDS $\geq 3$ ) children was 2.56 times higher than in mildly obese $(2 \leq$ BMI-SDS $<3)$ children. These results highlight that obesity is still an important trigger of NAFLD, although NAFLD and NASH can be found in the normal BMI population.

At the same time, our results demonstrated that the incidence of NASH in males was significantly higher than in females (14\% vs. $2.4 \%$ ), and gender was still a risk factor for $\mathrm{NASH}$ after adjusting for age, obesity and other components of the metabolic syndrome $(O R=4.94,95 \%$ CI (1.4117.35)). The gender difference in the distribution of NASH is similar to the results in adults. However, the reasons for this are not clear so far. It is possible that the fat distribution is more likely to accumulate in the viscera in males, which is more likely to cause metabolic disorders compared with subcutaneous fat, and that estrogen can improve the insulin sensitivity of adipose tissue in females [28].

\section{NAFLD, cardiovascular risk and metabolic syndrome}

In the present study, the NAFLD children showed higher cardiovascular risk and more metabolic syndromes than non-NAFLD children with obesity. This result is consistent to that reported in a previous case-control analysis [11]. The NAFLD children were more likely to develop abnormal glucose, insulin, triglycerides and HDL cholesterol than non-NAFLD children with matched age, sex and BMI [11]. A study covering 400 obese children also revealed that abnormal hepatic echo was associated with systolic and diastolic dysfunction [29]. Metabolic syndrome is a collection of cardiovascular risk factors that can predict diabetes and cardiovascular disease better than any single component. More and more evidence has shown that a large proportion of children with NAFLD meet the diagnostic standard of metabolic syndrome, suggesting that these children will develop diabetes and cardiovascular diseases in the future. This belief was supported by a 14-year-long Swedish cohort study of NAFLD patients diagnosed by biopsies. There was a $9 \%$ prevalence of diabetes at baseline, and most patients $(78 \%)$ had developed impaired glucose tolerance or diabetes by the end of the 14-year period [18]. In the same study, the survival of NAFLD adults diagnosed by biopsy was lower than that of a matched control group, largely due to higher cardiovascular mortality [18]. Therefore, health care workers should pay more attention to the early identification of cardiovascular risk factors in the NAFLD population, which is helpful to facilitate targeted prevention and treatment strategies.

\section{NAFLD and insulin resistance}

We found that the risk of insulin resistance in the NASH group was significantly higher than that in the SS and SOB groups, and insulin resistance was a risk factor for NASH after adjusting for confounding factors. Many clinical studies suggest that insulin resistance is always associated with NAFLD in adults and children [30-33]. A biopsy-proven NAFLD study showed that $95 \%$ of children had insulin resistance [34]. In an experimental study, Bugianesi et al. found that adipose tissue is an important site for the development of insulin resistance, which can contribute to NAFLD [35]. However, the association between insulin resistance and NASH remains unclear. The pathogenesis of NAFLD is hepatocyte steatosis and hepatocyte injury, in which insulin resistance plays an important role in the development of NAFLD. As peripheral insulin resistance arouses in NAFLD patients, serum-free fatty acids, synthesized through the lipolysis of visceral fatty tissue and dietary fat, serve as the origin of hepatic triglycerides. Insulin resistance acts in metabolic disorders induced by free fatty acids and mitochondria. Lipid overload can also repress oxidative performances. Meanwhile, with the production of reactive oxygen species, cytokines are induced, inflammatory cells chemoattracted, and hepatic stellate cells activated, all leading to damage to hepatocytes [36]. Therefore, insulin resistance is involved in the occurrence and development of NAFLD and NASH. On account of the central role of insulin resistance in glucose metabolism, youth diagnosed with fatty liver need further evaluation to exclude diabetes or impaired glucose tolerance due to insulin resistance. 


\section{NAFLD and uric acid}

A growing number of clinical studies have shown that hyperuricemia is related to NAFLD in both adults and children [37-39]. In a recent study of adolescents, hyperuricemia independently predicted $[O R 2.5,95 \% C I$ (1.87-2.83)] the presence of NASH after adjustment for potential confounders [40]. A biopsy-proven NAFLD study also found that the higher the serum uric acid, the greater the steatosis grade and lobular inflammation [41]. Similar to previous studies, we confirmed that obese patients with hyperuricemia had a higher risk of NASH occurrence [OR 2.98, 95\% CI (1.14-7.76)]. Experimental studies observed that incubation of HepG2 cells with uric acid can increase intracellular triglycerides. The potential mechanisms may be that uric acid activates mitochondrial stress, subsequently activates endoplasmic reticulum stress and activates sterol regulatory element-binding protein $1 \mathrm{C}$, while uric acid can stimulate the NOD-like receptor family pyrin domain containing 3 inflammasomes to regulate hepatic steatosis and inflammatory response in NAFLD patients [42, 43].

\section{Limitations of the present study}

Firstly, we cannot confirm whether the presumed NASH patients do have abnormal hepatology, so we chose the combination of ultrasound and twice the upper limit of ALT to define NASH, in order to reduce the diagnostic error. Secondly, a total of 428 obese children were included in this study, nearly $70 \%$ being males. Thirdly, because of its cross-sectional nature, the causal relationship between NAFLD and cardiovascular risk factors was not fully explored. In addition, other potential factors such as dietary, lifestyle, and family genetic factors will be taken into account in future studies.

\section{Conclusion}

In this study, we investigated the clinical characteristics of NAFLD and NASH in children with obesity, as well as the associations between NAFLD and metabolic risk factors at a single center. Our findings indicated that the prevalence of NASH in children with obesity is associated with high BMI-SDS, gender, insulin resistance, and hyperuricemia. These findings highlight the need for monitoring and prevention strategies at an early stage for children with obesity. Further multi-center and prospective epidemiological studies are needed to determine the prevalence and development of NAFLD in children with obesity in China.

\section{Abbreviations}

ALT: Alanine transaminase; AST: Aspartate aminotransferase; BMI: Body mass index; BMI-SDS: Body mass index standard deviation score; Cl: Confidence interval; DBP: Diastolic blood pressure; F: Female; HDL: High-density lipoprotein; HOMA-IR: Homeostasis model assessment of insulin resistance; M: Male; NAFL: Nonalcoholic fatty liver; NAFLD: Nonalcoholic fatty liver disease;
NASH: Nonalcoholic fatty hepatitis; OR: Odds ratio; SBP: Systolic blood pressure; SOB: Simple obesity; SS: Simple steatosis; WHtR: Waist to height ratio

\section{Acknowledgements}

We are very grateful for the support from technicians in the clinical laboratory and ultrasound department of the Children's Hospital of Nanjing Medical University. We also thank the children and parents for their participation.

\section{Authors' contributions}

LP participated in the study design, data analysis and data interpretation and prepared the manuscript. SW, NZ, SZ and QL participated in the data collection. $\mathrm{XL}$ was responsible for the study design and revised the manuscript. All authors read and approved the final manuscript.

\section{Funding}

This research was supported by the Natural Science Foundation of China (81773421), Jiangsu Province Social Development Research (BE2015607) and Innovation Team of Jiangsu Health (CXTDA2017035). The funder had no role in the design of the study and collection, analysis, and interpretation of data and in writing the manuscript.

\section{Availability of data and materials}

The data used to support the findings of this study are available from the corresponding author upon request.

\section{Declarations}

Ethics approval and consent to participate

The study protocol was approved by the Medical Ethics Committee of the Children's Hospital of Nanjing Medical University (201412004.1). The parent(s) or caregiver(s) of all subjects provided written informed consent before inclusion in the study. Written assent was obtained for all children.

Consent for publication

Not applicable.

\section{Competing interests}

The authors declare no conflict of interest.

\section{Author details}

'Department of Children Health Care, Children's Hospital of Nanjing Medical University, 72 Guangzhou Road, Nanjing 210008, People's Republic of China. ${ }^{2}$ Department of Endocrinology, Children's Hospital of Nanjing Medical University, Nanjing 210008, People's Republic of China. ${ }^{3}$ Department of Ultrasonography, Children's Hospital of Nanjing Medical University, Nanjing 210008, China. ${ }^{4}$ Institute of Pediatric Research, Nanjing Medical University, Nanjing 210008, China.

Received: 23 August 2020 Accepted: 4 March 2021

Published online: 12 March 2021

\section{References}

1. Schwimmer JB, Deutsch R, Kahen T, Lavine JE, Stanley C, Behling C. Prevalence of fatty liver in children and adolescents. Pediatrics. 2006;118: 1388-93 https://doi.org/10.1542/peds.2006-1212.

2. Zhang W, Wei L. Prevalence of nonalcoholic fatty liver disease in Asia. Chin J Hepatol. 2013;21:801-4.

3. Anderson EL, Howe LD, Jones HE, Higgins JP, Lawlor DA, Fraser A. The prevalence of non-alcoholic fatty liver disease in children and adolescents: a systematic review and meta-analysis. PLoS One. 2015;10:e0140908 https:// doi.org/10.1371/journal.pone.0140908.

4. Cohen JC, Horton JD, Hobbs HH. Human fatty liver disease: old questions and new insights. Science. 2011;332:1519-23 https://doi.org/10.1126/ science. 1204265.

5. Angulo P. Nonalcoholic fatty liver disease. N Engl J Med. 2002;346:1221-31 https://doi.org/10.1056/NEJMra011775.

6. Roberts EA. Nonalcoholic steatohepatitis in children. Curr Gastroenterol Rep. 2003;5:253-9 https://doi.org/10.1007/s11894-003-0028-4.

7. Schwimmer JB, McGreal N, Deutsch R, Finegold MJ, Lavine JE. Influence of gender, race, and ethnicity on suspected fatty liver in obese adolescents. Pediatrics. 2005;115:e561-5 https://doi.org/10.1542/peds.2004-1832. 
8. Lavine JE, Schwimmer JB. Nonalcoholic fatty liver disease in the pediatric population. Clin Liver Dis. 2004;8:549-58, viii-ix https://doi.org/10.1016/j.cld.2 004.04.010.

9. Feldstein $A E$, Charatcharoenwitthaya $P$, Treeprasertsuk $S$, Benson JT, Enders $F B$, Angulo P. The natural history of non-alcoholic fatty liver disease in children: a follow-up study for up to 20 years. Gut. 2009;58:1538-44 https:// doi.org/10.1136/gut.2008.171280.

10. Molleston JP, White F, Teckman J, Fitzgerald JF. Obese children with steatohepatitis can develop cirrhosis in childhood. Am J Gastroenterol. 2002; 97:2460-2 https://doi.org/10.1111/j.1572-0241.2002.06003.x.

11. Schwimmer JB, Pardee PE, Lavine JE, Blumkin AK, Cook S. Cardiovascular risk factors and the metabolic syndrome in pediatric nonalcoholic fatty liver disease. Circulation. 2008;118:277-83 https://doi.org/10.1161/CIRCULATIONA HA.107.739920.

12. Schwimmer JB, Zepeda A, Newton KP, Xanthakos SA, Behling C, Hallinan EK, et al. Longitudinal assessment of high blood pressure in children with nonalcoholic fatty liver disease. PLoS One. 2014;9:e112569 https://doi.org/1 0.1371/journal.pone.0112569.

13. Adams LA, Lymp JF, St Sauver J, Sanderson SO, Lindor KD, Feldstein A, et al. The natural history of nonalcoholic fatty liver disease: a population-based cohort study. Gastroenterology. 2005;129:113-21 https://doi.org/10.1053/j.ga stro.2005.04.014

14. Ekstedt M, Hagstrom $H$, Nasr P, Fredrikson M, Stal P, Kechagias S, et al. Fibrosis stage is the strongest predictor for disease-specific mortality in NAFLD after up to 33 years of follow-up. Hepatology. 2015;61:1547-54 https://doi.org/10.1002/hep.27368.

15. Vos MB, Abrams SH, Barlow SE, Caprio S, Daniels SR, Kohli R, et al. NASPGH AN clinical practice guideline for the diagnosis and treatment of nonalcoholic fatty liver disease in children: recommendations from the expert committee on NAFLD (ECON) and the North American Society of Pediatric Gastroenterology, Hepatology and Nutrition (NASPGHAN). J Pediatr Gastroenterol Nutr. 2017;64:319-34 https://doi.org/10.1097/MPG. 0000000000001482.

16. Schwimmer JB, Newton KP, Awai HI, Choi LJ, Garcia MA, Ellis LL, et al. Paediatric gastroenterology evaluation of overweight and obese children referred from primary care for suspected non-alcoholic fatty liver disease. Aliment Pharmacol Ther. 2013;38:1267-77 https://doi.org/10.1111/apt.12518.

17. Farrell GC, Wong WW, Chitturi S. NAFLD in Asia--as common and important as in the west. Nat Rev Gastroenterol Hepatol. 2013;10:307-18 https://doi. org/10.1038/nrgastro.2013.34.

18. Ekstedt M, Franzen LE, Mathiesen UL, Thorelius L, Holmqvist M, Bodemar G, et al. Long-term follow-up of patients with NAFLD and elevated liver enzymes. Hepatology. 2006:44:865-73 https://doi.org/10.1002/hep.21327.

19. Mullen MC, Shield J. Pocket guide to pediatric weight management. 2nd ed; 2018.

20. McCarthy HD, Jarrett KV, Crawley HF. The development of waist circumference percentiles in British children aged 5.0-16.9 y. Eur J Clin Nutr. 2001;55:902-7 https://doi.org/10.1038/sj.ejcn.1601240.

21. Saadeh S, Younossi ZM, Remer EM, Gramlich T, Ong JP, Hurley M, et al. The utility of radiological imaging in nonalcoholic fatty liver disease. Gastroenterology. 2002;123:745-50 https://doi.org/10.1053/gast.2002.35354.

22. Dhuper S, Cohen HW, Daniel J, Gumidyala P, Agarwalla V, St Victor R, et al. Utility of the modified ATP III defined metabolic syndrome and severe obesity as predictors of insulin resistance in overweight children and adolescents: a cross-sectional study. Cardiovasc Diabetol. 2007;6:4 https:// doi.org/10.1186/1475-2840-6-4.

23. Song P, Li X, Gasevic D, Flores AB, Yu Z. BMI, waist circumference reference values for Chinese school-aged children and adolescents. Int J Environ Res Public Health. 2016;13 https://doi.org/10.3390/ijerph13060589.

24. Subspecialty Group of Endocrinologic H, Metabolic Diseases, The Society of Pediatrics Chinese Medical Association, Subspecialty Group of Cardiology TSoPCMA, Subspecialty Groups of Child Health Care TSOPCMA. The definition of metabolic syndrome and prophylaxis and treatment proposal in Chinese children and adolescents. Chin J Pediatr. 2012;50:420-2.

25. Matthews DR, Hosker JP, Rudenski AS, Naylor BA, Treacher DF, Turner RC. Homeostasis model assessment: insulin resistance and beta-cell function from fasting plasma glucose and insulin concentrations in man. Diabetologia. 1985;28:412-9 https://doi.org/10.1007/bf00280883.

26. Keskin M, Kurtoglu S, Kendirci M, Atabek ME, Yazici C. Homeostasis model assessment is more reliable than the fasting glucose/insulin ratio and quantitative insulin sensitivity check index for assessing insulin resistance among obese children and adolescents. Pediatrics. 2005;115:e500-3 https:// doi.org/10.1542/peds.2004-1921.

27. Ford ES, Li C, Cook S, Choi HK. Serum concentrations of uric acid and the metabolic syndrome among US children and adolescents. Circulation. 2007; 115:2526-32 https://doi.org/10.1161/CIRCULATIONAHA.106.657627.

28. Denzer C, Thiere D, Muche R, Koenig W, Mayer H, Kratzer W, et al. Genderspecific prevalences of fatty liver in obese children and adolescents: roles of body fat distribution, sex steroids, and insulin resistance. J Clin Endocrinol Metab. 2009;94:3872-81 https://doi.org/10.1210/jc.2009-1125.

29. Alp H, Eklioglu BS, Atabek ME, Karaarslan S, Baysal T, Altin H, et al. Evaluation of epicardial adipose tissue, carotid intima-media thickness and ventricular functions in obese children and adolescents. J Pediatr Endocrinol Metab. 2014;27:827-35 https://doi.org/10.1515/jpem-2013-0306.

30. Jain V, Jana M, Upadhyay B, Ahmad N, Jain O, Upadhyay AD, et al. Prevalence, clinical \& biochemical correlates of non-alcoholic fatty liver disease in overweight adolescents. Indian J Med Res. 2018;148:291-301 https://doi.org/10.4103/ijmr.IJMR_1966_16.

31. Pacifico L, Celestre M, Anania C, Paolantonio P, Chiesa C, Laghi A. MRI and ultrasound for hepatic fat quantification:relationships to clinical and metabolic characteristics of pediatric nonalcoholic fatty liver disease. Acta Paediatr. 2007;96:542-7 https://doi.org/10.1111/j.1651-2227.2007.00186.x.

32. Rajindrajith S, Pathmeswaran A, Jayasinghe C, Kottahachchi D, Kasturiratne A, de Silva ST, et al. Non-alcoholic fatty liver disease and its associations among adolescents in an urban, Sri Lankan community. BMC Gastroenterol. 2017;17:135 https://doi.org/10.1186/s12876-017-0677-7.

33. Tominaga $K$, Fujimoto $E$, Suzuki $K$, Hayashi M, Ichikawa M, Inaba $Y$. Prevalence of non-alcoholic fatty liver disease in children and relationship to metabolic syndrome, insulin resistance, and waist circumference. Environ Health Prev Med. 2009;14:142-9 https://doi.org/10.1007/s12199-008-0074-5.

34. Schwimmer JB, Deutsch R, Rauch JB, Behling C, Newbury R, Lavine JE. Obesity, insulin resistance, and other clinicopathological correlates of pediatric nonalcoholic fatty liver disease. J Pediatr. 2003;143:500-5 https:// doi.org/10.1067/S0022-3476(03)00325-1.

35. Bugianesi E, Gastaldelli A, Vanni E, Gambino R, Cassader M, Baldi S, et al. Insulin resistance in non-diabetic patients with non-alcoholic fatty liver disease: sites and mechanisms. Diabetologia. 2005;48:634-42 https://doi. org/10.1007/s00125-005-1682-x.

36. Neuschwander-Tetri BA. Non-alcoholic fatty liver disease. BMC Med. 2017;15: 45 https://doi.org/10.1186/s12916-017-0806-8.

37. Ouyang X, Cirillo P, Sautin Y, McCall S, Bruchette JL, Diehl AM, et al. Fructose consumption as a risk factor for non-alcoholic fatty liver disease. J Hepatol. 2008:48:993-9 https://doi.org/10.1016/j.jhep.2008.02.011.

38. Sirota JC, McFann K, Targher G, Johnson RJ, Chonchol M, Jalal DI. Elevated serum uric acid levels are associated with non-alcoholic fatty liver disease independently of metabolic syndrome features in the United States: liver ultrasound data from the National Health and Nutrition Examination Survey. Metabolism. 2013;62:392-9 https://doi.org/10.1016/j.metabol.2012.08.013.

39. Sullivan JS, Le MT, Pan Z, Rivard C, Love-Osborne K, Robbins K, et al. Oral fructose absorption in obese children with non-alcoholic fatty liver disease. Pediatr Obes. 2015;10:188-95 https://doi.org/10.1111/ijpo.238.

40. Mosca A, Nobili V, De Vito R, Crudele A, Scorletti E, Villani A, et al. Serum uric acid concentrations and fructose consumption are independently associated with NASH in children and adolescents. J Hepatol. 2017;66:10316 https://doi.org/10.1016/j.jhep.2016.12.025.

41. Petta S, Camma C, Cabibi D, Di Marco V, Craxi A. Hyperuricemia is associated with histological liver damage in patients with non-alcoholic fatty liver disease. Aliment Pharmacol Ther. 2011;34:757-66 https://doi.org/1 0.1111/j.1365-2036.2011.04788.x.

42. Choi YJ, Shin HS, Choi HS, Park JW, Jo I, Oh ES, et al. Uric acid induces fat accumulation via generation of endoplasmic reticulum stress and SREBP-1C activation in hepatocytes. Lab Investig. 2014;94:1114-25 https://doi.org/10.1 038/labinvest.2014.98.

43. Wan X, Xu C, Lin Y, Lu C, Li D, Sang J, et al. Uric acid regulates hepatic steatosis and insulin resistance through the NLRP3 inflammasomedependent mechanism. J Hepatol. 2016;64:925-32 https://doi.org/10.1016/j. jhep.2015.11.022.

\section{Publisher's Note}

Springer Nature remains neutral with regard to jurisdictional claims in published maps and institutional affiliations. 